\title{
Plasma Medicine Research in Costa Rica: Oveniew of First Steps
}

\author{
Laura Barillas, ${ }^{\mathrm{a}, \mathrm{b}}$ Jose Asenjo, ${ }^{\mathrm{a}}$ Erika Alfaro-Mayorga, ${ }^{\mathrm{c}}$ Maria Ines Chaves- \\ Rodriguez, ${ }^{\mathrm{d}}$ Stephen James Petretti, ${ }^{a}$ Dayanna Méndez, ${ }^{a}$ Jaime Mora, ${ }^{a}$ Isaac \\ Porras-Navarro, ${ }^{\text {a }}$ Miguel Rojas-Chaves, ${ }^{d}$ Victor Ivan Vargas, ${ }^{\mathrm{a}, \mathrm{e},},{ }^{*}$ \& Isaac Felipe \\ Céspedes-Camacho ${ }^{f}$
}

aPlasma Laboratory for Fusion Energy and Applications, Instituto Tecnológico de Costa Rica, Costa Rica; 'bchool of Electromechanical Engineering, Instituto Tecnológico de Costa Rica, Costa Rica; 'Faculty of Dentistry, Universidad de Costa Rica, San José, Costa Rica; ' $S c h o o l$ of Biology and Biotechnology Research Center, Instituto Tecnológico de Costa Rica, Costa Rica; eSchool of Physics, Instituto Tecnológico de Costa Rica, Costa Rica; fSchool of Chemistry, Instituto Tecnológico de Costa Rica, Cartago, Costa Rica

*Address all correspondence to: Victor Ivan Vargas, Instituto Tecnológico de Costa Rica, P.O. Box 159-7050, Cartago, Costa Rica; Tel: +506 2550-2794; Fax: +506 2550-2000, E-mail: ivargas@tec.ac.cr

\begin{abstract}
In the last decade, the various challenges, novelty, and potential of the emerging field of plasma medicine have caught the attention of several plasma physics and engineering groups, companies, and governments around the world. Among them, in 2013, the Plasma Laboratory for Fusion Energy and Applications of the Instituto Tecnológico de Costa Rica (Costa Rica Institute of Technology, TEC) started its first steps on this novel field motivated by numerous reasons, including the declaration of national interest in the field of plasma physics and applications given by the government of the Republic of Costa Rica. The present work briefly describes the first steps in Costa Rica's plasma medicine projects, which include plasma sterilization, antibacterial textiles, cell viability by atmospheric pressure non-equilibrium plasma (APNP), bioactive and antibacterial plasma-sprayed coatings, and atmospheric pressure plasma applications in dentistry.
\end{abstract}

KEY WORDS: plasma medicine, Costa Rica, plasma spray, dentistry, plasma, bioactive, sterilization, thin film deposition

\section{INTRODUCTION}

Plasma medicine is an innovative emerging field in which plasma science and technology, biology, and medicine come together to respond to fundamental questions regarding the interaction between living organisms and plasma and to overcome various related technological challenges. ${ }^{1}$ In the last decade, the novelty and potential of this field has caught the attention of various plasma physics and engineering groups, companies, and governments around the world to perform research in this area. In fact, according to von Woedtke et al. ${ }^{2}$ : "[. . . ] a survey among 148 German companies realized in 2004 by VDI Technologiezentrum Düsseldorf, Germany, predicted the field of maximum growth of future plasma applications to be medical technology, biotechnology and pharmacy, respectively."

For the above reason, in 2013, the Plasma Laboratory for Fusion Energy and Applications (founded in 2008) of the Instituto Tecnológico de Costa Rica (Costa Rica 
Institute of Technology, TEC) began its first steps into this novel field motivated by recent developments. One of them corresponds to the large life sciences cluster in Costa Rica, composed by more than 60 medical devices producers, including six of the top 20 largest in the world, becoming one of the leaders in MedTech investment of the region by being the second largest exporter of medical devices in Latin America and among the top seven suppliers to the U.S. market. Furthermore, the life sciences sector has continued to experienced incredible dynamism in Costa Rica, growing to represent $23 \%$ of the country's total exports of goods in 2015 . In addition, data show that, in the last decade, exports of precision and medical equipment has grown almost $280 \%$ and medical devices were the number-one industrial export good of Costa Rica in 2015, accounting for $4 \%$ of the total GDP. ${ }^{3}$

Another motivation has been the launch of the first master's program in medical devices engineering by TEC in Latin America, which has driven more cooperation between different working groups of the industry and academia, such as the Plasma Laboratory for Fusion Energy and Applications (PlasmaTEC), the Biotechnology Research Center (CIB) from TEC, and the Faculty of Dentistry from Universidad de Costa Rica. In addition, the declaration of national interest in the field of plasma physics and applications given by the government of the Republic of Costa Rica in 2011 (decree no. 36569-MICIT) at present has mostly received attention for researchers in the field of high-temperature plasmas for fusion as a future energy source with the commissioning of the first Latin American stellarator, the Stellarator of Costa Rica 1, but is a great precedent for the plasma science and technology field overall.

In this sense, the present work briefly describes the first steps in Costa Rica's plasma medicine projects, which include plasma sterilization, antibacterial textiles, cell viability by atmospheric pressure non-equilibrium plasma (APNP), bioactive and antibacterial plasma-sprayed coatings, and atmospheric pressure plasma (APP) applications in dentistry. Future steps are also discussed.

\section{VACUUM PLASMA STERILZATION}

There is a continuing need to create efficient, cheap, and environmentally friendly processes and plasma technology offers a platform on which applications with such characteristics can be developed. In the case of sterilization, reactors involving physical or chemical means are used widely in the industry, with some key processes posing a risk to the safety of the user. Plasma sterilization comes to overcome the risks that traditional methods may have, making sterilization possible in processes and places where human safety and lack of materials prevent the implementation of other methods.

International research efforts have provided convincing evidence that the key factor for a successful sterilization is presented by the ultraviolet radiation in the wavelength range of $160 \mathrm{~nm}<\lambda<240 \mathrm{~nm}$ generated by means of a plasma discharge onto open surfaces and electrically neutral active particles for complex shape instruments. ${ }^{4}$ It has also been shown that effective sterilization is possible using air or other gases (argon, nitrogen, oxygen, carbon dioxide, hydrogen) at relatively low power density $\left(\mathrm{W}_{\mathrm{D}}=0.003 / 0.03 \mathrm{~W} / \mathrm{cm}^{3}\right){ }^{5}$ 


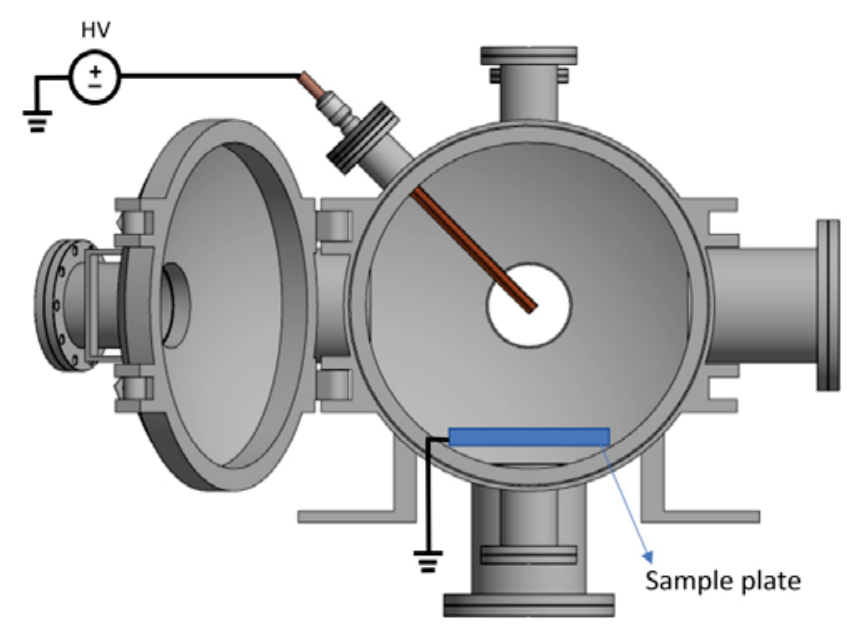

FIG. 1: Experimental setup for vacuum plasma sterilization

In 2013, the first experiment related to plasma medicine of the Plasma Laboratory for Fusion Energy and Applications of the Costa Rica Institute of Technology was designed, focused on performing sterilization on a scalpel blade with a biological agent added. An oxygen DC plasma was generated at $1 \mathrm{kV}$ and a current of $500 \mathrm{~mA}$, with a working pressure set at $20.0 \pm 0.1$ mTorr in a $50 \mathrm{~L}$ vacuum using the setup shown in Fig. 1.

The biological agent Pseudomonas spp. was used. These bacteria are a genus of bacilli that are generally very mobile due to the one or more flagella that they possess. Due to their mobility, it was possible to determine qualitatively the level of mortality in the samples. ${ }^{6}$ Samples were treated for four different time periods and the results obtained are shown in Table 1.

As seen in the table, $100 \%$ mortality was achieved after 5 minutes of exposure to the plasma, which proves the effectiveness of the process. Nonetheless, the samples show a deterioration of the culture medium (agar) as the exposure time increases. Further studies are needed using other microorganisms and evaluating the effect of the process quantitatively.

TABLE 1: Results of vacuum plasma sterilization bacteria mortality for different treatment times

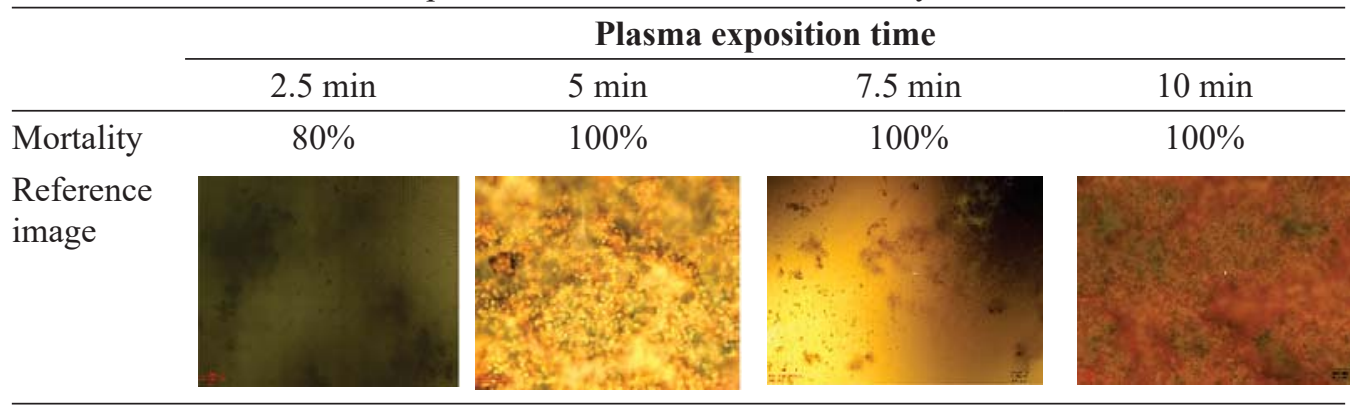

Volume 7, Issue 3, 2017 


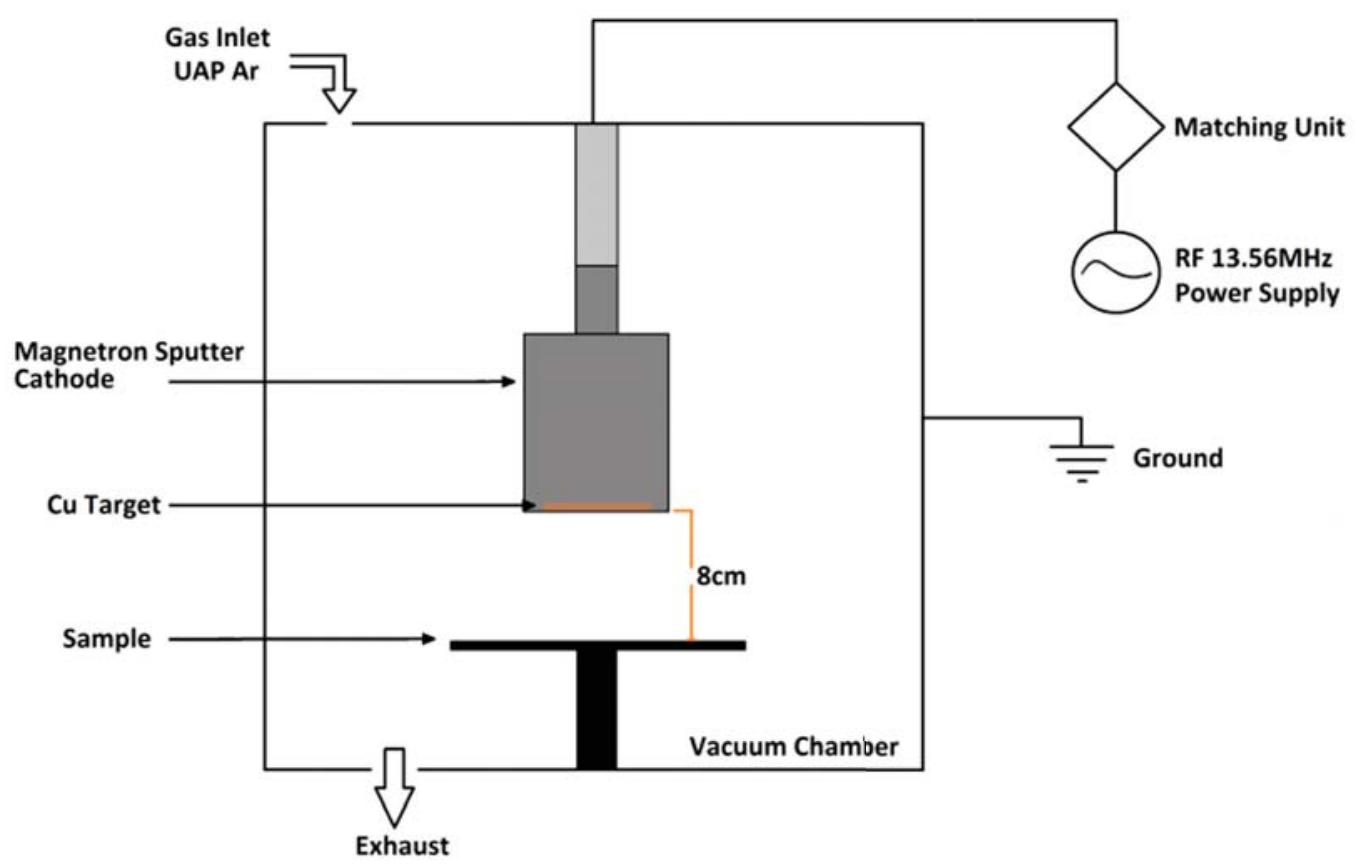

FIG. 2: Experimental setup for antibacterial textiles treatment (Reprinted with permission from IOP Publishing, Copyright 2015) ${ }^{7}$

\section{ANTIBACTERIAL TEXTILS: COPPER DEPOSTIION ON COTION FBERS}

The recent development of antimicrobial textiles has become of great use in the medical field in response to the properties of fabrics serving as an excellent medium for the adherence, transfer, and propagation of microbial species. The undesirable effect of microbial growth on textiles commonly results in the generation of body odor, the compounds of which degrade certain textiles and may produce an adverse effect on human health. Some studies in the past have demonstrated the effectiveness of the biocidal properties of copper oxide when deposited onto fabrics. ${ }^{8}$ It has been shown in a series of studies that cotton treated with copper oxide resulted in a 99\% reduction of the organisms Staphylococcus aureus, Escherichia coli, and Candida albicans, while having a 100\% mortality of the mite Dermatophagoides farinae.

The main goal of the experiments, performed in 2014 and published in 2015 by Segura et al. ${ }^{7}$ at PlasmaTEC, was to test qualitatively the antimicrobial action of copper $\mathrm{Cu}$ on fabrics taking into consideration information from the preparation and characterization of radiofrequency (RF)-sputtered $\mathrm{Cu}$ films on cotton by the usage of a magnetron sputter source, as shown in Fig. 2 (using the same $50 \mathrm{~L}$ vacuum chamber as in Fig. 1).

$\mathrm{Cu}$ layers were deposited on cotton substrate by means of an RF magnetron sputtering gun and a $\mathrm{Cu}$ target with $99.995 \%$ purity and 1 inch in diameter with a distance 


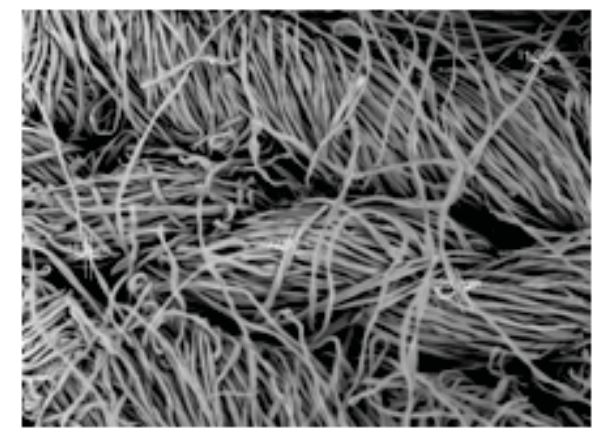

FIG. 3: Cotton fibers without $\mathrm{Cu}$ sputtering (Reprinted with permission from IOP Publishing, Copyright 2015) ${ }^{7}$

$\sim 8 \mathrm{~cm}$ between the $\mathrm{Cu}$ target and cotton substrate. The cotton samples were cleaned beforehand via isopropyl alcohol immersion for about 1 hour and dried in a vacuum. Using argon as a medium gas, a discharge power of $50 \mathrm{~W}$ was applied.

The experiments were performed in two stages; first, characterizing the deposition in the fibers for different times and then carrying out qualitative and quantitative analysis of the antibacterial properties of the treated textiles. Figure 3 shows cotton fibers without $\mathrm{Cu}$ sputtering. The initial cotton structure has a high degree of interweave, thus resulting in a non-uniform surface. In addition, there exists a wide range of fiber thicknesses, with the average thickness being $24.15 \mu \mathrm{m}$.

Strains of E. coli ATCC 35218 and S. aureus were used for the qualitative and quantitative analysis of the antibacterial properties. The organisms were inoculated onto a tryptic soy agar plate. After proving the effectiveness of the treatment with the qualitative method, a quantitative analysis was performed to confirm effectiveness. The methodology is shown in Table 2.

During the qualitative test, a decrease in the growth of bacteria on contact with $\mathrm{Cu}$ was observed; the fabric samples with longer sputtering time presented lower growth rate of $E$. coli colonies due to the higher concentration of $\mathrm{Cu} .^{7}$ The quantitative test also

TABLE 2: Qualitative and quantitative analysis methods of determining antibacterial properties

Method 1: The cotton fabric samples were placed on a petri dish immediately after Qualitative inoculation and incubated at $35^{\circ} \mathrm{C}$ for $24 \mathrm{~h}$. The petri dishes were covered with a lid to prevent contamination and evaporation.

Method 2: $\quad$ The cotton fabric samples were sterilized to eliminate any external source Quantitative of microbial contamination that might interfere with the results of the test. Samples were inoculated with bacteria in $20 \mu \mathrm{L}$ of saline solution. After $5 \mathrm{~min}$ of bacterial exposure, the sample was recovered. Several dilutions were made in saline solution and then inoculated on a sterile plate with nutritive agar by the extension technique. After incubating the plates with nutritive agar for $24 \mathrm{~h}$ at $37^{\circ} \mathrm{C}$, the colony-forming units were counted. 
TABLE 3: Quantitative results for bacteria growth

\begin{tabular}{lllll}
\hline & & \multicolumn{3}{c}{ UCF dilution } \\
\cline { 3 - 5 } Sample & Microorganism & $\mathbf{1 0}^{-\mathbf{1}}$ & $\mathbf{1 0}^{-\mathbf{2}}$ & $\mathbf{1 0}^{-\mathbf{3}}$ \\
\hline Control & E. coli & Uncountable & Uncountable & 50 \\
& S. aureus & Uncountable & 49 & 5 \\
1-min deposition & E. coli & Uncountable & $\mathrm{NC}$ & $\mathrm{NC}$ \\
& S. aureus & 1 & $\mathrm{NC}$ & $\mathrm{NC}$ \\
\hline
\end{tabular}

shows a decrease in the growth of bacteria and results are shown in Table 3 and Fig. 4.

The deposition of cupric metals onto textiles in order to achieve antibacterial properties seems to be a viable method for reducing microbial contamination on cotton substrate; however, the durability of the properties, adherence of the deposition, and the effects that it has on contact with skin are future research topics for PlasmaTEC.

\section{APNP INTERACTIVITY ON CEL VIABIUTY OF MURINE RBROBLASTS CULTURED IN VITRO}

The differentiated interaction between the specific components of the atmospheric pressure non-equilibrated plasma with the structural and physiological variants of living cells constitutes the basis of the emerging and fast-growing field of plasma medicine. ${ }^{9}$ These interactions can lead to the stimulation or inhibition of the cells functions that could be translated into therapeutic applications. Different plasma sources and devices have been used in different potential applications in the biomedical field, mainly through the plasma jet and dielectric barrier discharge (DBD) devices that work at atmospheric pressure. ${ }^{2,10}$

Currently, an important part of the studies devoted to the application of APP in human or animal studies have been conducted in the field of dermatology. ${ }^{11}$ However, the main purposes of plasma medicine have been to study the interaction of the plasma and its outcomes on wound-healing processes, cancer treatments, endoscopy, and dentistry. ${ }^{2,12,13}$

The replacement of tissues and organs has constituted a great challenge for the research and clinical communities. Therefore, the development of in vitro cell, tissue, and potentially organ culture has become a promise to address the clinical challenges associated with patients' biological particularities in replacing lost tissues. However, there is still a lack of key elements that can improve the efficacy and efficiency of the techniques at the laboratory and clinical level. One of these is the induction of exogenous cells to better adapt to the wound environment in order to accelerate the healing process. The multidisciplinary work that can be done in the plasma medicine field can provide new tools that deliver positive results on this matter. ${ }^{11}$

The application of low-temperature plasma on different surfaces has shown that modifications of the treated area can be performed in ways that can be used to our advan- 


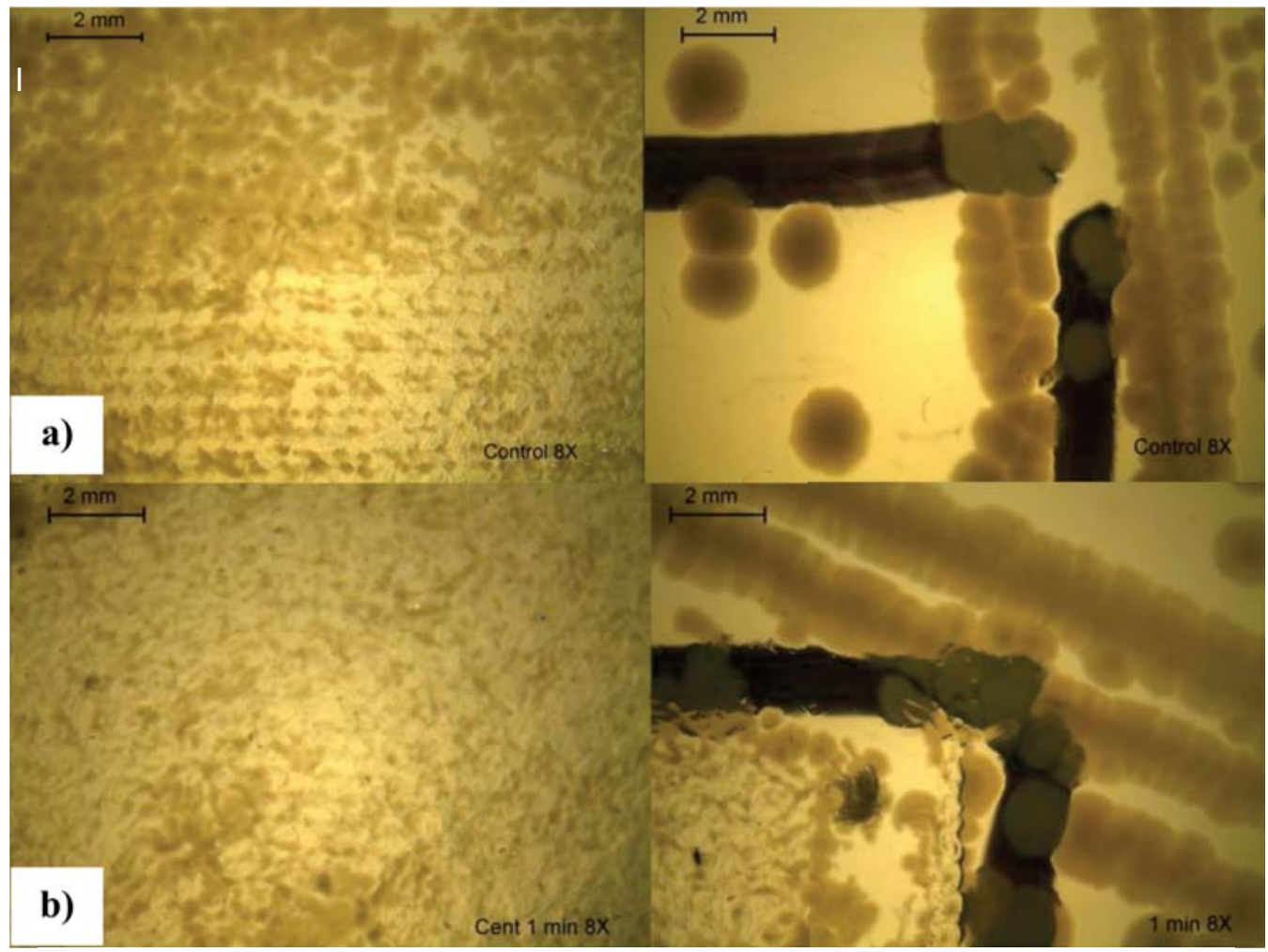

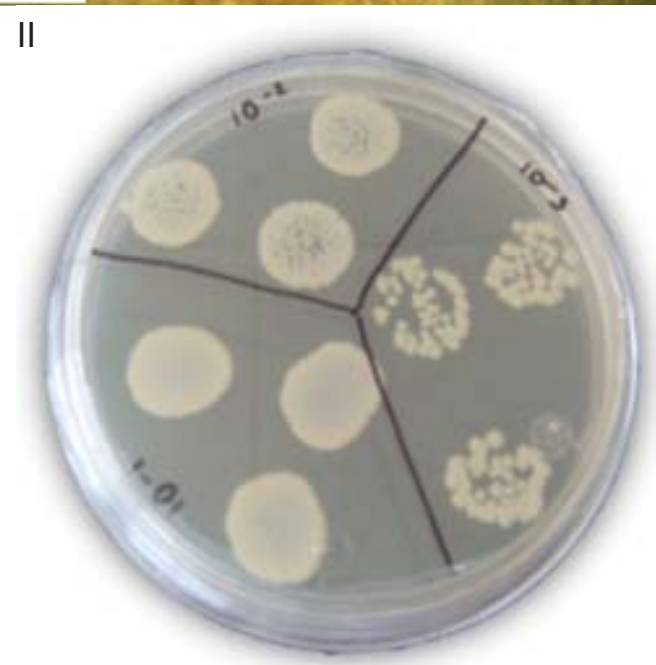

(a)

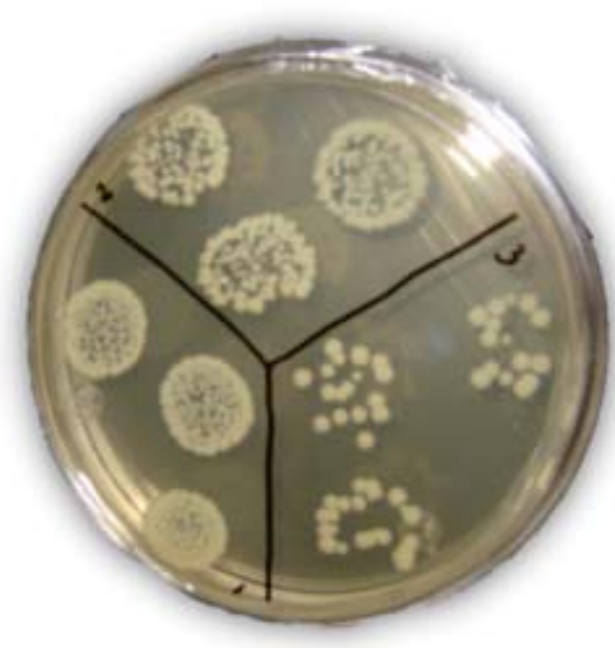

(b)

FIG. 4: Growth of E. coli during the tests for different times of deposition. (I) Qualitative results of bacterial growth in the contact area for each sample: (a) control, (b) 4 min. (II) E. coli growth in petri dish to count colony-forming units for: (a) control sample, (b) Cu deposition for $1 \mathrm{~min}$ for quantitative results. (Reprinted with permission from IOP Publishing, Copyright 2015) ${ }^{7}$

Volume 7, Issue 3, 2017 
tage. This is the case in the application of plasma into the wound bed. Not only has this been shown to decrease the bacteria populations that cause infections selectively and promptly, but it also stimulates the cells to regenerate the bed in a more efficient woundhealing process. ${ }^{13}$ Conversely, stimulation of the in vitro cultured cells to be transplanted into the wound could further improve the regeneration progress.

On this same path, the Plasma Laboratory for Fusion Energy and Applications and the Tissue Engineering and Cellular Biology Laboratory at the Costa Rica Institute of Technology have joined efforts to study the interaction of atmospheric pressure nonequilibrated plasma in the processes of wound healing with potential therapeutic applications in skin tissue engineering in an ongoing project. The long-term aim is to evaluate the feasibility of implementing a combined strategy of plasma irradiation and the system for the production of in vitro cultured epidermal cells applied to various dermatological wound types.

The current objective of this joint venture is to design a DBD-type plasma device and study the effect of its plasma discharge on in vitro cultured murine fibroblasts as a primary approach to evaluating the biological outcomes of the irradiation on cell migration, viability, and proliferation. The DBD device consists of a set of parallel electrodes covered by one alumina or plastic dielectric in which the atmospheric plasma is generated. A discharge is generated after applying a sinusoidal current, which in turn produces the plasma. The configuration is enclosed in an acrylic box, as seen in Fig. 5, which is saturated with an atmosphere of an ionizing gas, in this case, helium. One of the main advantages that the design provides is the production of a uniform discharge onto a flat surface that corresponds to a monolayer culture of cells.

Because this is an ongoing project, biological tests are currently being performed in order to assess the basal conditions of irradiation, such as voltage and time doses, as well as the distance between the electrode and the cell culture. The mid-term goal would be to assay these parameters in more complex systems including epidermal cells co-cultures and animal models. These preclinical data would set the basis to aim for clinical trials on patients with cutaneous wounds.

\section{BIOACTIVE AND ANTIBACTERIAL PLASMA-SPRAYED COATINGS ON POLYMERS FOR POTENTIALORTHOPEDIC AND TISSUE ENG INEERING APPUCATIONS}

Biomaterials are natural or synthetic substances that interact temporally or permanently with the body. Within these biomaterials, polymers in the medical devices field can play an important role due to weight, cost, and mechanical performance,${ }^{14}$ among other factors. Some applications of these materials in the orthopedics area are, for example, fracture fixation implants, scaffolds for bone fracture engineering, and spinal cages for intervertebral disk replacement in spinal surgery, among many others. Conversely, new manufacturing and materials processing techniques and technologies, mainly additive manufacturing or 3D printing, have allowed a wide range of medical devices to change from being expensive and generic (devices in which "one size fits all") to being cus- 


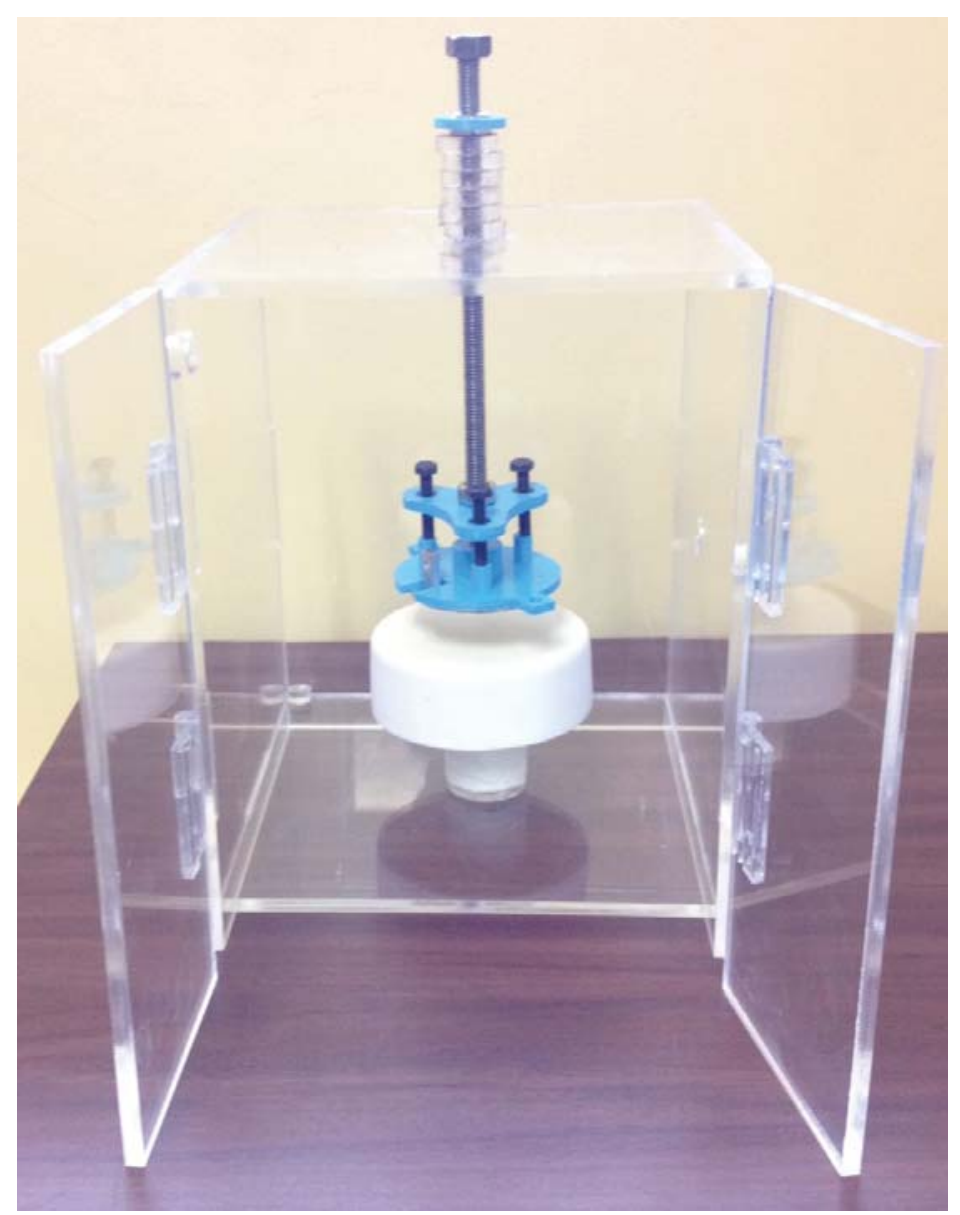

FIG. 5: DBD device developed for the studies of in vitro cultured murine fibroblasts irradiated with APNP

tomized and more affordable options. Furthermore, they have allowed biopolymers to present new applications with great potential in the customized orthopedics industry and tissue engineering. Implants that were impossible to manufacture with traditional machining methods due to their complex geometries are now being 3D printed to deliver fairly fast and affordable well-fitted solutions. ${ }^{15}$

In most cases, it is widely sought for orthopedic devices to support bone in-growth and to enhance the osseointegration with the remaining bone or tissue structure, as well as to avoid postsurgical complications such as infections due to microbes or bacteria. Although it is possible to 3D print small implants and scaffolds constituted entirely by bioactive materials such as hydroxyapatite (HA) and calcium phosphates, which enhance osseoconductivity and support bone ingrowth with the reaming tissue, ${ }^{15}$ they present the problem of low mechanical strength and are limited to non-load-bearing or 


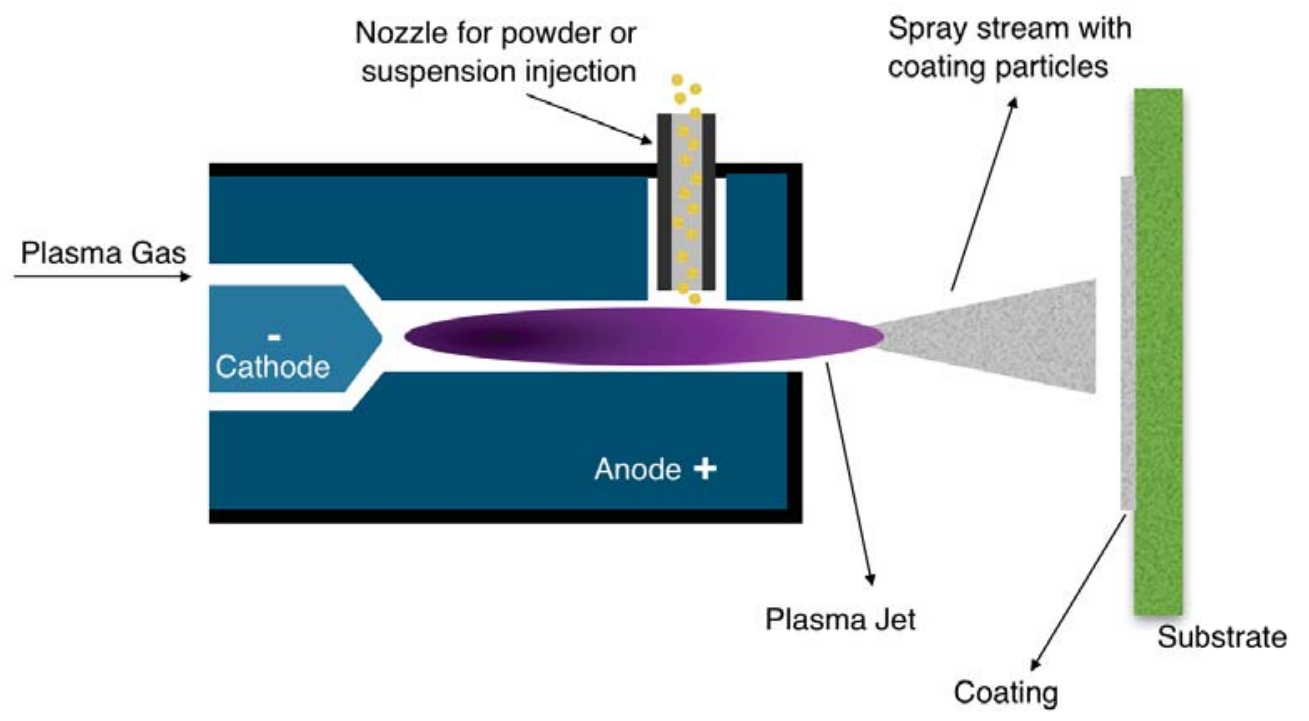

FIG. 6: Plasma spray schematic (Used with permission from Barillas et al., Copyright 2016) ${ }^{19}$

low-load-bearing applications. ${ }^{16}$ Therefore, the best idea is to design composite implants that take advantage of the features of bioactive materials and the characteristics of polymers, such as their strength and manufacturability.

To accomplish the above-mentioned purposes of proper osseoconductivity and bacterial minimization, medical devices can be coated by different means and materials, such as $\mathrm{HA}$, titanium dioxide $\left(\mathrm{TiO}_{2}\right)$, and $\mathrm{Cu}$. Among different thermal spray techniques, atmospheric plasma spray (APS) is the most widely used technology for surfacing implants with highly osseointegrating coatings such as HA. ${ }^{17}$ APS is a technology of rapid solidification, in which a material is introduced into a plasma jet, generated by a DC arc, melted, and propelled against a surface to be coated, ${ }^{18}$ as shown in Fig. 6.

Despite of the advantages of plasma-sprayed coatings, such as high deposition rates, economy, and the advantage that it can coat almost any substrate with any material that has a well-defined melting point, ${ }^{18,20,21}$ this technology has been primarily applied to metallic substrates and, unfortunately, only a few studies are available on polymers and composite materials. ${ }^{17,22}$ Therefore, the aim of this study was to use APS to coat with bioactive and antimicrobial materials different polymer substrates commonly used for tissue engineering that at the same time are suitable for additive manufacturing processing [e.g., polylactic acid (PLA), polyvinyl alcohol (PVA), polylactic-L acid (PLLA) and poly-ether-ether-ketone (PEEK)], presenting the potential for applications in the customized orthopedic industry.

Specifically, the objectives of the project include:

- Design and implement a low-energy plasma spray (LESP) system design to deposit different materials over polymer substrates. 

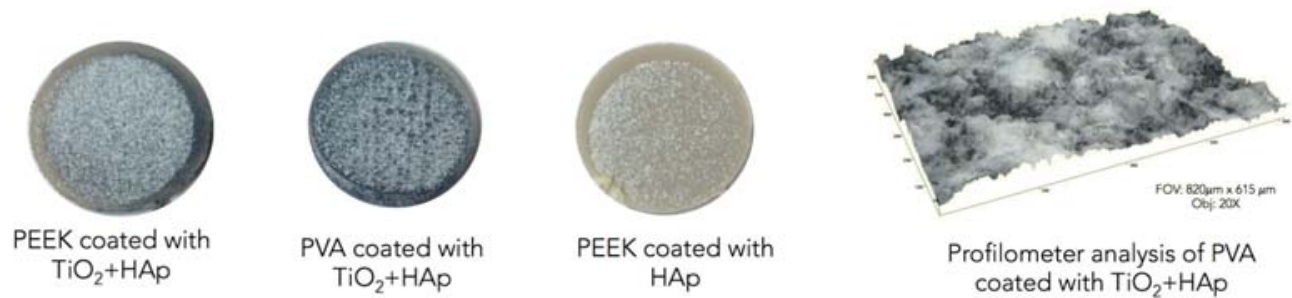

FIG. 7: Plasma-sprayed polymer samples using a plasma power of $\sim 42 \mathrm{~kW}$. Also shown is an optical profilometer graph of one of the samples.

- Perform coating experiments with $\mathrm{HA}, \mathrm{TiO}_{2}$ (as bonding/antimicrobial agent), and copper (antimicrobial agent), over polymers commonly used in orthopedics and tissue engineering applications (e.g., PLA, PVA, PLLA, and PEEK).

- Determine the optimal experimental parameters to deposit bioactive and antimicrobial materials over polymers without altering significantly their surface and shape.

- Perform biological tests of MG63 osteoblast growth and bacteria proliferation (S. aureus) over the plasma-sprayed surfaces to evaluate the viability for potential orthopedic and tissue engineering applications.

The project is being developed at the Plasma Laboratory for Fusion Energy and Applications of the Costa Rica Institute of Technology, and in cooperation with the Leibniz Institut für Plasmaforschung und Technologie e.V. (INP Greifswald), Germany.

The first experiments of the project performed at INP Greifswald show promising outcomes for the polymer PEEK when coated with in $\mathrm{HA}$ only, $\mathrm{HA}+\mathrm{TiO}_{2}$, and $\mathrm{HA}+\mathrm{TiO}_{2}+\mathrm{Cu}(3 \% \mathrm{wt})$ because the polymer is not affected by the thermal energy of the plasma jet after several coatings (more than one layer is needed to accomplish a closed coating) using industrial plasma spray equipment such as Sultzer Metco ${ }^{\mathrm{TM}}$, Plasma source F4MB-XL, System Platform MultiCoat ${ }^{\mathrm{TM}}$, with input power $\sim 42 \mathrm{~kW}$, net plasmatron power of 25-30 kW. Images of some samples are shown in Fig. 7.

However, for PLA especially and for PVA, the results are poor due to their low melting point (below $180^{\circ} \mathrm{C}$ and $230^{\circ} \mathrm{C}$ ), at least after several coatings. Nonetheless, with a single coating, the results are more satisfying, suggesting that possibly with a lower plasmatron power level and a modification of the parameters, the outcomes could improve. Therefore, a LESP system is being designed and implemented at PlasmaTEC using non-conventional or non-commercially available equipment for APS. A first experiment was conducted at PlasmaTEC using modified plasma cutter equipment instead of a conventional plasma spray system to deposit HA. ${ }^{15}$ Aside from PEEK, PLA, and PVA, titanium (Ti-6Al-7Nb) and aluminum samples were also coated to compare them with results demonstrated in similar investigations, with the aim of assessing the functionality of the equipment and feasibility of the experiment in order to prove this concept. The results showed a successful deposition of HA to a certain extent on polymer and metallic 

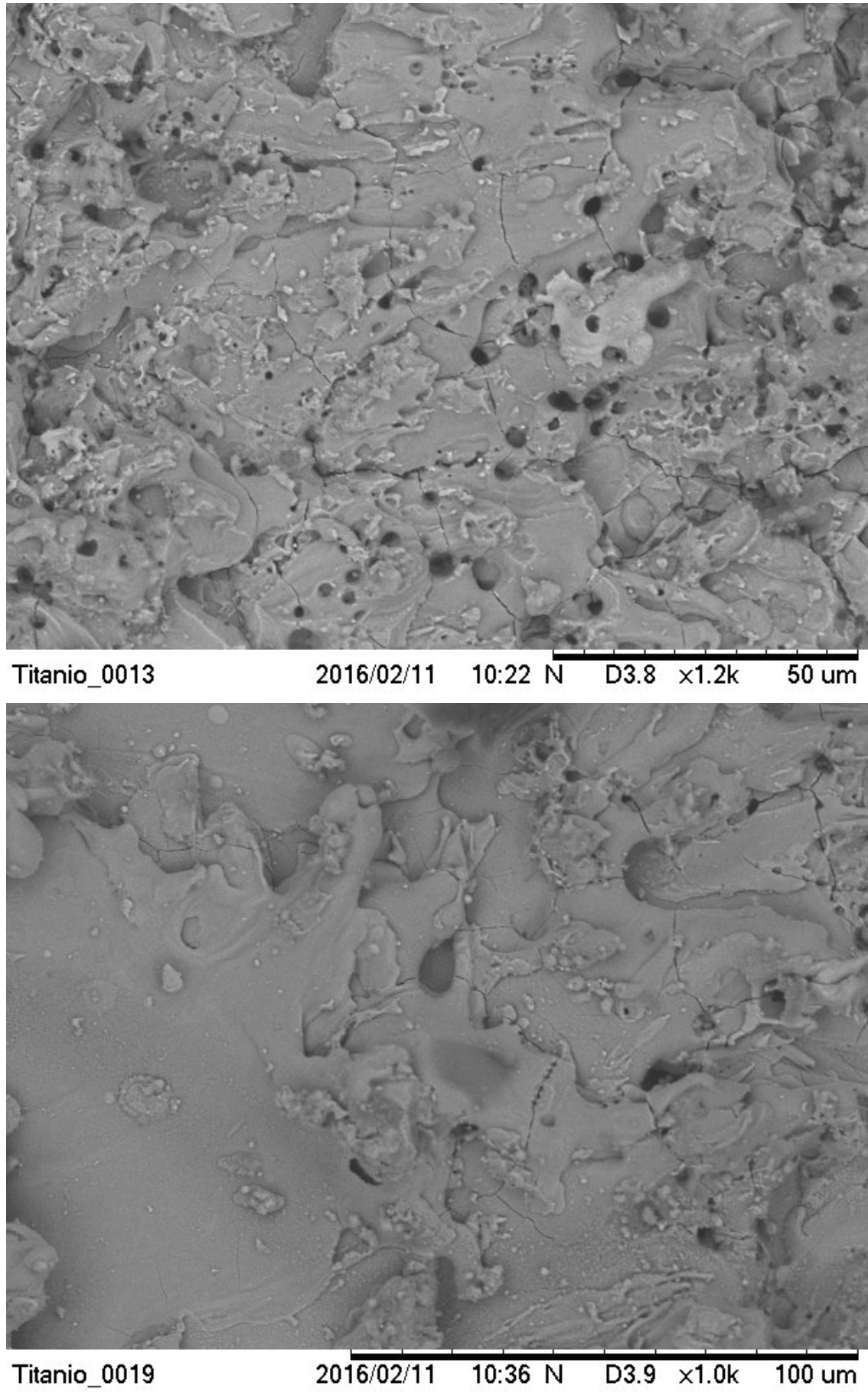

FIG. 8: Ti-6Al-7Nb sample coated with HA using nonconventional plasma spray equipment. Splat morphology, porosity, and uniformity are signs of satisfactory results. 
substrates (Fig. 8), which indicates the potential for application of widespread coated areas if instrumental variables can be further controlled. ${ }^{15}$

Future steps and projects of this investigation include: optimization of the LESP system and operational parameters, biological in vitro essays, and trials with other deposition materials and substrates.

\section{APPUCATIONSIN DENTISTRY: PHYSICO-CHEMICAL CHARAC TERIZATION OF DENTAL SURFACES, RESTORATIVE MATERIALS, AND INHIBIORY EFECTON METAUOPROTIENASES}

The longevity and integrity of the adhesion to dentine of adhesive restorations has been questioned in recent years. The interphase system between the adhesive system and the dentine is known as the hybrid layer. Degradation of this layer has been found in in vitro studies up to 1 year after the restoration. ${ }^{23}$

De Munk stated in 2005 that "in the past decade, considerable evidence has accumulated, saying that the union created in dentin with adhesives of the resin base could be not as durable as conjectured." ${ }^{24}$ In addition, it has been reported that hybrid layer degradation is related to its long-term weakening. ${ }^{23-28}$

The quality and durability of this interphase has been associated with the capacity of the monomer of the resin to penetrate in de-mineralized dentin by the acid, among other things. Insufficient penetration of monomer resin results in unprotected zones left in the collagen, which can convert into collagen hydrolysis by derived metalloproteinases (MMPs) from the matrix of the dentin. In dental cavities, there are multiple interacting factors, including bacteria and the surface that has to be modified or cleaned with acid so that an adhesive system can give retention to the restorative material. ${ }^{29}$

Dentine is the vital part of the tooth formed by odontoblasts, which secrete a matrix of collagen that is mineralized. It can be described as a humid composite of collagen, mineralized tissue, and tubules. The quantity of these canals increases from 15,000 to $20,000 / \mathrm{mm}^{2}$ in the amelo-dentine union and from 45,000 to 65,000 close to the pulp.

The adhesive systems used in dentistry to bond restorative materials to dentin can be total etch (two steps) or self-adhesive (one step) and, in both cases, it has been shown that they have the influence to activate the MMPs after adhesion. ${ }^{30}$ The activated MMPs can hydrolyze the unprotected fibers of collagen, which are left unfilled during the formation of the hybrid layer with the passage of time. Degradation of the hybrid layer in vitro has been seen up to 1 year after the restoration. ${ }^{23}$ All efforts to modify the force of union or to reduce possible deterioration of the hybrid layer will necessarily result in a better sealing and duration of the interphase dentine restoration, which requires an adhesive system for its retention.

Therapy with nonthermic plasma or APP has been demonstrated to have great efficiency in the elimination of bacteria and modification of tissues and surfaces. ${ }^{31}$ In dentistry, several applications of APP have been studied, such as disinfection of cavities and root canals, ${ }^{29,32}$ use in adhesion of compound resins to teeth showing an improvement in the strength of adhesion, ${ }^{9,33}$ adhesion force of fiber posts, ${ }^{34}$ and effect on microorganisms 
of the oral cavity such as Lactobacillus casel, Streptococcus mutans, C. albicans, and E. coli, among others. ${ }^{35}$ In these works, a reduction in the bacterial population was made with increased effect associated with the increase of time of exposure. APP has also been used for whitening, demonstrating an increment of the action attributed to the production of hydrogen peroxide. ${ }^{36}$ As a treatment of the surface of materials, APP increased the force of adhesion to materials for indirect restorations associated with the production of carboxyl groups on the surface of ceramic and better hydrophilicity that augmented when the exposure time applied increased. ${ }^{37}$

Although there is interest in the many possible applications of APP in the field of medicine and dentistry, doubts still exist in the mechanisms that act in the interaction between the plasma and tissues ${ }^{38}$; therefore, the purpose of this investigation was to determine the physico-chemical effect of exposure of the dentin surface to plasma for different periods of the time.

\section{VII.CONCLUSIONS AND NEXTSTIEPS}

As we have discussed, several projects in the field of plasma medicine are ongoing in Costa Rica. Although some of them are not as complex or sophisticated compared with existing studies, they are important step in order to bring Costa Rica, and subsequently all of Latin America, into the field and to demonstrate to the research community in the region that this a field full of opportunities with questions ready to be answered. Therefore, this field should be supported not only by the academia, but also by industry and competent governmental institutions. Next steps will be sophistication of the current research plus new, derived projects in the field of cancer research, skin treatment, plasma agriculture focused on tropical crops and species, and plasma food processing.

\section{ACKNOWHEGMENT}

This work was presented at the $6^{\text {th }}$ International Conference on Plasma Medicine with the support given by the Vicerrectoría de Investigación y Extensión of the Costa Rica Institute of Technology through CONARE's Internationalization Fund.

\section{REFERENCES}

1. Laroussi M, Fridman A, Satava RM. Plasma medicine (editorial). Plasma Process Polym. 2008;5(6):501.

2. von Woedtke T, Reuter S, Masur K, Weltmann KD. Plasmas for medicine. Phys Rep. 2013;530(4):291320.

3. Latin America's leading Med Tech hub [Internet]. CINDE Costa Rican Investment Promotion Agency [cited 2017 Feb14]. Available from: http://www.cinde.org/en/sectors/life-sciences.

4. Khomich VA, Soloshenko IA, Tsiolko V V, Mikhno IL. Investigation of principal factors of the sterilization by plasma DC glow discharge. Proc Int Congr Plasma Phys. 1998;22:2745-48.

5. Soloshenko IA, Tsiolko VV, Khomich VA, Shchedrin AI, Ryabtsev AV, Bazhenov VY, Mikhno IL. Sterilization of medical products in low-pressure glow discharges. Plasma Phys Rep. 2000;26(9):84553.

6. Brenner DJ, Krieg NR, Staley JT. Bergey's manual of systematic bacteriology. Volume 1. Baltimore 
(MD): Williams \& Wilkins; 1984. p. 233-35.

7. Segura G, Guzmán P, Zuñiga P, Chaves S, Barrantes Y, Navarro G, Asenjo J, Guadamuz S, Vargas VI, Chaves J. Copper deposition on fabrics by rf plasma sputtering for medical applications. J Phys Conf Ser. 2015;591(1):1-7.

8. Gupta D, Bhaumik S. Antimicrobial treatments for textiles. Indian J Fibre Text Res. 2007;32(2):25463.

9. Kong MG, Kroesen G, Morfill G, Nosenko T, Shimizu T, Van Dijk J, Zimmermann JL. Plasma medicine: An introductory review. New J Phys. 2009;11:1-35.

10. Weltmann KD, Kindel E, von Woedtke T, Hähnel M, Stieber M, Brandenburg R. Atmospheric-pressure plasma sources: Prospective tools for plasma medicine. Pure Appl Chem. 2010;82(6):1223-37.

11. Heinlin J, Isbary G, Stolz W, Morfill G, Landthaler M, Shimizu T, Steffes B, Nosenko T, Zimmermann JL, Karrer S. Plasma applications in medicine with a special focus on dermatology. J Eur Acad Dermatology Venereol. 2011;25(1):1-11.

12. Heinlin J1, Morfill G, Landthaler M, Stolz W, Isbary G, Zimmermann JL, Shimizu T, Karrer S. Plasma medicine: possible applications in dermatology. J Dtsch Dermatol Ges. 2010;8(12):968-76.

13. Karrer S, Arndt S. Plasma medicine in dermatology: Mechanisms of action and clinical applications. Der Hautarzt. 2015;66(11):819-28.

14. McKeen LW. Plastics used in medical devices. In: Handbook of polymer applications in medicine and medical devices, 1st ed. New York: Elsevier; 2014: 21-53.

15. Barillas L, Cubero-Sesin J, Guillén-Girón T. Plasma sprayed hydroxyapatite coatings on $3 \mathrm{~d}$ printed polymer substrates for orthopedic applications: a preliminary study. In: Proceedings of the International Thermal Spray Conference 2016; 2016 May; Shanghai. Düsseldorf: DVS-Berichte; 2016: 840-5.

16. Bose S, Vahabzadeh S, Bandyopadhyay A. Bone tissue engineering using 3D printing. Mater Today. 2013;16(12):496-504.

17. Beauvais S, Decaux O. Plasma sprayed biocompatible coatings on PEEK implants. Therm Spray. 2007 Glob Coat Solut. 2007;371-7.

18. Heimann RB. Plasma spray coating: principles and applications. 2nd ed. plasma spray coating: principles and applications. Weinheim: Wiley-VCH Verlag GmbH \& Co. KGaA; 2008.

19. Barillas L, Cubero-Sesin J, Guillén-Girón T. Plasma Sprayed hydroxyapatite coatings on 3d printed polymer substrates for orthopedic applications: a preliminary study [poster presentation]. International Thermal Spray Conference 2016. 2016 May; Shanghai.

20. Heimann RB. Plasma-sprayed hydroxylapatite-based coatings: chemical, mechanical, microstructural, and biomedical properties. J Therm Spray Technol. 2016;25(5):827-50.

21. Bosco R, Van Den Beucken J, Leeuwenburgh S, Jansen J. Surface engineering for bone implants: a trend from passive to active surfaces. Coatings. 2012;2(3):95-119.

22. Auclair-Daigle C, Bureau MN, Legoux JG, Yahia L. Bioactive hydroxyapatite coatings on polymer composites for orthopedic implants. J Biomed Mater Res Part A. 2005;73(4):398-408.

23. Pashley DH, Tay FR, Yiu C, Hashimoto M, Breschi L, Carvalho RM, Ito S. Collagen degradation by host-derived enzymes during aging. J Dent Res. 2004;83(3):216-21.

24. De Munck J, Van Landuyt K, Peumans M, Poitevin A, Lambrechts P, Braem M, Van Meerbeek B. A critical review of the durability of adhesion to tooth tissue: Methods and results. J Dent Res. 2005;84(2):118-32.

25. De Munck J, Mine A, Van den Steen PE, Van Landuyt KL, Poitevin A, Opdenakker G, Van Meerbeek B. Enzymatic degradation of adhesive-dentin interfaces produced by mild self-etch adhesives. Eur $\mathrm{J}$ Oral Sci. 2010;118(5):494-501.

26. Osorio R, Yamauti M, Ruiz-Requena ME, Toledano M. MMPs activity and bond strength in deciduous dentine-resin bonded interfaces. J Dent. 2013;41(6):549-55.

27. Van Landuyt KL, De Munck J, Mine a, Cardoso M V, Peumans M, Van Meerbeek B. Filler debonding and subhybrid-layer failures in self-etch adhesives. J Dent Res. 2010;89(10):1045-50.

28. Liu Y, Tjäderhane L, Breschi L, Mazzoni A, Li N, Mao J, Pashley DH, Tay FR. Limitations in bond-

Volume 7, Issue 3, 2017 
ing to dentin and experimental strategies to prevent bond degradation. J Dent Res. 2011;90:953-68.

29. Sladek REJ, Stoffels E, Walraven R, Tielbeek PJA., Koolhoven RA. Plasma treatment of dental cavities: a feasibility study. IEEE Trans Plasma Sci. 2004;32(4):2002-5.

30. Van Meerbeek B, Conn LJ, Duke ES, Eick JD, Robinson SJ, Guerrero D. Correlative transmission electron microscopy examination of nondemineralized and demineralized resin-dentin interfaces formed by two dentin adhesive systems. J Dent Res. 1996;75(3):879-88.

31. McCombs GB, Darby ML. New discoveries and directions for medical, dental and dental hygiene research: low temperature atmospheric pressure plasma. Int J Dent Hyg. 2010;8(1):10-15.

32. Lu X, Cao Y, Yang P, Xiong Q, Xiong Z, Xian Y, Pan Y. An RC plasma device for sterilization of root canal of teeth. IEEE Trans Plasma Sci. 2009;37(5):668-73.

33. Dong X, Ritts AC, Staller C, Yu Q, Chen M, Wang Y. Evaluation of plasma treatment effects on improving adhesive-dentin bonding by using the same tooth controls and varying cross-sectional surface areas. Eur J Oral Sci. 2013;121(4):355-62.

34. Yavirach P, Chaijareenont P, Boonyawan D, Pattamapun K, Tunma S, Takahashi H, Arksornnukit M. Effects of plasma treatment on the shear bond strength between fiber-reinforced composite posts and resin composite for core build-up. Dent Mater J. 2009;28(6):686-92.

35. Rupf S, Lehmann A, Hannig M, Schäfer B, Schubert A, Feldmann U, Schindler A. Killing of adherent oral microbes by a non-thermal atmospheric plasma jet. J Med Microbiol. 2010;59(2):206-12.

36. Lee HW, Kim GJ, Kim JM, Park JK, Lee JK, Kim GC. Tooth bleaching with nonthermal atmospheric pressure plasma. J Endod. 2009;35(4):587-91.

37. Han GJ, Chung SN, Chun BH, Kim CK, Oh KH, Cho BH. Effect of the applied power of atmospheric pressure plasma on the adhesion of composite resin to dental ceramic. J Adhes Dent. 2012;14(5):46169.

38. Stoffels E, Sakiyama Y, Graves DB. Cold atmospheric plasma: Charged species and their interactions with cells and tissues. IEEE Trans Plasma Sci. 2008;36(4):1441-57. 